\title{
Retraction Note to: Histopathological features of cutaneous and gastric habronemiasis in horse
}

\author{
Fatemeh Amininajafi ${ }^{1}$ - Mohammad Reza Mehrara ${ }^{2}$ - Arman Hosseini ${ }^{3}$. \\ Rooholla Fattahi $^{4} \cdot$ Mehdi Taghizadeh $^{5} \cdot$ Sardar Hasanzadeh $^{6}$
}

Published online: 4 November 2016

(C) Indian Society for Parasitology 2016

Retraction Note to: J Parasit Dis (July-Sept 2016) 40(3):945-947

DOI 10.1007/s12639-014-0611-7

This article has been retracted at the request of the Editorin-Chief, The Indian Society for Parasitology (ISP), and the Publisher per the Committee on Publication Ethics guidelines. There is strong reason to believe that the peer review process was compromised, and the authors have plagiarized parts from the following article:

Yarmut Y, Brommer H, Weisler S, Shelah M, Komarovsky O, Steinman A, Ophthalmic and cutaneous habronemiasis in a horse: Case report and review of the literature. Israel Journal of Veterinary Medicine. 2008; 63:3 87-90.

As such the validity of the content of this article cannot be verified.

The online version of the original article can be found under doi:10.1007/s12639-014-0611-7.

Fatemeh Amininajafi

vadieamini@yahoo.com

1 Department of Pathology, Faculty of Veterinary Medicine, Tehran University, Tehran, Iran

2 Doctor of Veterinary Medicine, Tehran, Iran

3 Department of Clinical Science, Faculty of Veterinary Medicine, Tehran University, Tehran, Iran

4 Department of Parasitology, Faculty of Veterinary Medicine, University of Tehran, Tehran, Iran

5 Faculty of Veterinary Medicine, Urmia University, Urmia, Iran

6 College of Agricultural, Tehran University, Tehran, Iran 